\title{
EIA BASED COMPARATIVE URBAN TRAFFIC NOISE ANALYSIS BETWEEN OPERATIONAL AND UNDER CONSTRUCTION PHASE PUBLIC TRANSPORT CORRIDOR
}

\author{
Rajeev Kumar Mishra ${ }^{1}$, Ankita Shukla ${ }^{2}$, Manoranjan Parida ${ }^{3}$, Santosh Rangnekar ${ }^{4}$ \\ ${ }^{1}$ Department of Environmental Engineering, Delhi Technological University, Delhi-110 042, India \\ ${ }^{2}$ J.K. Infrastructure Limited, DMRC Project, Delhi, India \\ ${ }^{3}$ Centre for Transportation Systems (CTRANS), Indian Institute of Technology, Roorkee, India \\ ${ }^{4}$ Department of Management Studies, Indian Institute of Technology, Roorkee, India
}

Received 5 September 2013; accepted 28 July 2014

\begin{abstract}
Delhi has a population of 16.75 million and is increasing at a rapid rate. This increase in population has enhanced the need for public transport. In Delhi, this need for public transport is served mainly by buses, auto rickshaws, a rapid transit system, taxis and suburban railways. Delhi has one of the highest road densities in India. Buses are the most popular means of transport catering to about $60 \%$ of the total demand. In order to meet the transport demand in Delhi, the State and the Union government started the construction of a mass rapid transit system, including the Delhi Metro. By the application of various data and public response, the paper accentuates the qualitative discussion on impacts of mass rapid transit system (MRTS) corridor on land use and social aspects of lives of residents and road users. It also proposes certain mitigating measures for that meticulous condition. The analysis and survey outcome explain about the exceeded level of noise level as compared to CPCB standards. The share of public transport in total noise pollution is smaller than private but still exceeds the standards. Such problem demands the design of noise barrier along the corridor to curb the noise pollution.
\end{abstract}

Keywords: CPCB, EIA, MRTS, public transport.

\section{Introduction}

Population growth, increasing urbanization and rising motorization are the most important factors common to India and other developing countries. The entire urban population of India increased from 683 million in 1981 to 1210 million in 2011, whereas the urban population of Delhi increased from 6.22 million in 1981 to 16.75 million in 2011 (Economic Survey of Delhi, 2012-2013). The stridently increasing levels of motor vehicle ownership and use, in particular, have resulted in alarming levels of congestion, air pollution and noise pollution. The number of vehicles on Delhi road has been increased by $135.6 \%$ in the last 13 years from 3.2 million in 1999-2000 to over 7.45 million by 2011-12 (Economic Survey of Delhi, 2012-2013). Due to high occupancy on Delhi road, there is little scope of future expansion of road length. To accommodate the increasing vehicular population, additional space is increasingly

\footnotetext{
${ }^{1}$ Corresponding author: rajeevkumarmishra@dce.edu
} 
sought to be created either over or beneath the road, i.e. flyovers and underpasses. Due to short of more infrastructure and fast life in megacities of India, the urban environment has now become enormously crowdy, busy as well as noisy and as a result the millions of people living in the major metropolitan areas are suffering from the adverse impacts of noise pollution. Noise is an endemic problem in large metropolis and has received relatively little attention as a potential health hazard in the developing world (Galilea and Ortúzar, 2005). Noise in big cities is considered by the World Health Organization (WHO) to be the third most hazardous type of pollution, right after air and water pollution (Zannin, 2008; Mohammadi, 2009). Traffic has been recognized as the main noise source in cities, being this problematic more important in developing countries (Kumar et al., 1998; Zannin, 2008; Mohammadi, 2009; Zekry, 2009; Jose et al., 2012; Novačko et al., 2014). Nowadays, the United States Environmental Protection Agency considers noise as an environmental problem affecting the largest number of people on the planet, after air and water pollution (United State Environmental Protection Agency, 2001). To reduce such kind of environmental pollution, instead of giving more incentive and road space to private vehicles, there is a need to promote public transport like mass rapid transit system as well as bus rapid transit system. Due to this reason, before strating a new project, an environmental impact assessment (EIA) is carried out to estimate its impact on the surrounding environment in the short, medium and long term. Even after operationalisation of the project, the EIA is essential to ensure that the transportation system meets the environmental requirements for which it was designed. Based on this environmental impact analysis, it may be possible for an individual to draw up an environmental management plan that would ensure impact monitoring and mitigation planning. Delhi, the national capital of India, has significant dependence on its transport infrastructure. The city has a developed public transport system, which is undergoing rapid modernization and expansion. Public transport system as seen today has undergone various phases of transformations with the prime focus on improving environmental quality. In present days besides traffic air pollution problems and traffic congestion, people are very much worried about the traffic noise pollution problem and metro vibration problem. The current study is a comparative noise analysis between the operational and under construction phase of metro corridor.

\section{Objective}

The objective of this paper is to present a comparative environmental impact assessment based noise pollution study of operational as well as under construction phase public transport corridor in Delhi with emphasis on the mass rapid transit system. To predict the noise level at selected locations, the FHWA (Federal Highway Administration) model has been used during the study. In addition to this, the paper also includes qualitative discussion on impacts of metro corridors on land use and social aspects of lives of residents and road users. This analysis has been performed by taking the perception of people living in the vicinity of operational corridor. The relevant perception based data has been collected through a questionnaire survey among the residents of corridor. This paper also discusses the method to minimize the exceeded noise level through the installation of noise barriers along the road of metro corridor at Rithala on both side of road near to residential and commercial area. 


\section{Field Study and Data Collection}

To carry out the study, two locations, one is operational i.e. Rithala and another one is under construction phase i.e. Qutubminar are selected in Delhi (Fig. 1). These two sites represent two distinct types of land use patterns i.e. Commercial and Residential land use (Rithala) and Commercial and Agricultural land use (Qutubminar). Due to their distinct land use pattern, it is very necessary to estimate the impact of these corridors over a large section of the population living in the vicinity of the corridors.

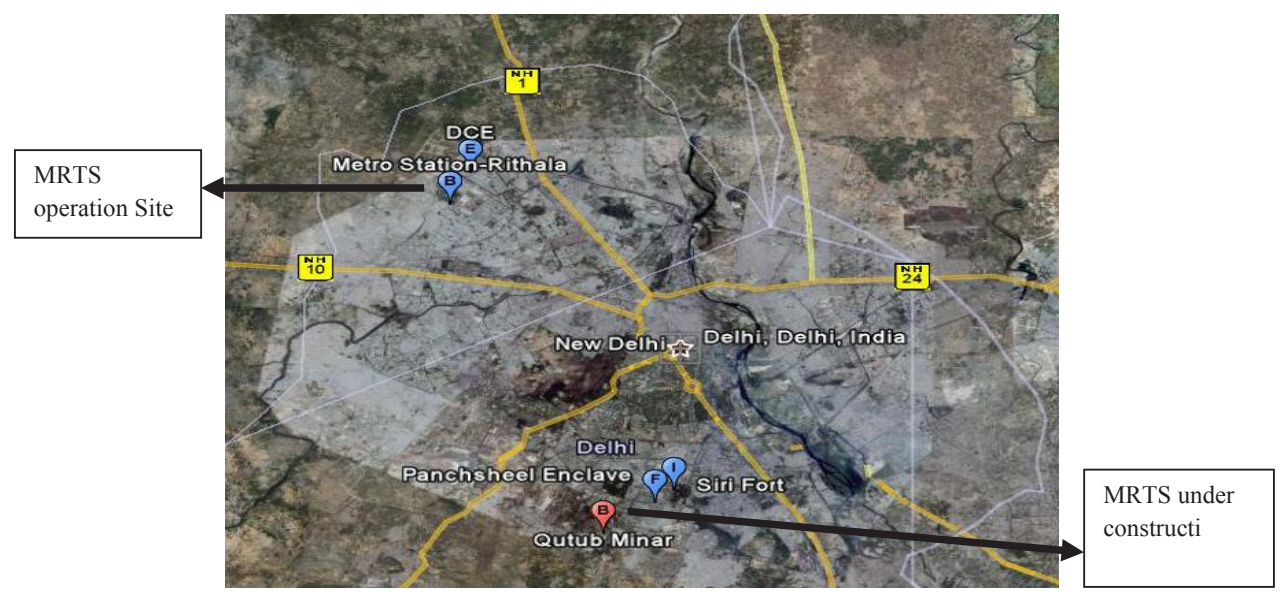

Fig. 1.

Google Earth View of Study Locations in Delhi

During the study various data like traffic volume, ambient noise level, spot speed are collected in both the direction of vehicle movement which are presented in Table 1,2 , 3, 4, 5, 6, 7 and 8 respectively. Table 1, 2 and Table 3, 4 depict the classified traffic volume of different categories of vehicles in both the direction at Rithala and Qutubminar location. At both the locations the number of cars and two wheelers are observed much higher in comparison to other categories of vehicles. After comparing both the locations, the number of cars and two-wheelers are found much higher at Qutubminar followed by Rithala site. Likewise the ambient noise level study has also been carried out for eight hours at both the locations in both directions (Table 5 and Table 6). Different noise parameters like L10, L50, L90 and Leq are calculated for each location in each direction. From the study, it is found that the Qutubminar location due to under construction phase shows higher equivalent noise level than the Ritala site (under operation). As per their land use pattern and CPCB standard (Table 8), the equivalent noise level of both the locations exceeds the prescribed standard which represents the presence of noise pollution. To predict the noise level at both the locations, the spot speed study has also been conducted for the span of eight hours in both directions of each location. The average speed data of all categories of vehicles are shown in Table 7. To analyze the actual scenario and its impact on residential 
as well as road users, a social impact study has also been conducted to know the public opinion about the impact of operational as well as under construction corridors. This survey is conducted among people by taking opinion about some specified pertinent questions related to environmental impact of corridors. The response collected has been taken as basis to analyze the social impact survey.

\section{Table 1}

Traffic Volume (veh/h) at Rithala Direction 1

\begin{tabular}{|l|l|l|l|l|l|l|l|l|}
\hline Time & Car/Jeep & Mini Bus & Bus & $\begin{array}{l}\text { Scooter/ } \\
\text { Motor Cycle }\end{array}$ & $\begin{array}{l}\text { Mini } \\
\text { Truck }\end{array}$ & Truck & $\begin{array}{l}\text { Tractor/ } \\
\text { Trailers }\end{array}$ & $\begin{array}{l}\text { Auto- } \\
\text { Rickshaw }\end{array}$ \\
\hline $9.00-10: 00$ & 454 & 23 & 13 & 471 & 0 & 1 & 1 & 47 \\
\hline $10: 00-11: 00$ & 677 & 34 & 25 & 593 & 5 & 0 & 3 & 73 \\
\hline $11: 00-12: 00$ & 631 & 29 & 19 & 709 & 22 & 9 & 2 & 136 \\
\hline $12: 00-13: 00$ & 717 & 38 & 25 & 525 & 25 & 4 & 3 & 142 \\
\hline $13: 00-14: 00$ & 652 & 27 & 22 & 348 & 12 & 1 & 0 & 136 \\
\hline $15: 00-16: 00$ & 537 & 33 & 22 & 344 & 13 & 5 & 2 & 133 \\
\hline $16: 00-17: 00$ & 589 & 39 & 19 & 446 & 20 & 3 & 4 & 148 \\
\hline $17: 00-18: 00$ & 474 & 40 & 20 & 693 & 9 & 0 & 1 & 166 \\
\hline
\end{tabular}

\section{Table 2}

Traffic Volume (veh/h) at Rithala Direction 2

\begin{tabular}{|l|l|l|l|l|l|l|l|l|}
\hline Time & Car/Jeep & Mini Bus & Bus & $\begin{array}{l}\text { Scooter/ } \\
\text { Motor Cycle }\end{array}$ & $\begin{array}{l}\text { Mini } \\
\text { Truck }\end{array}$ & Truck & $\begin{array}{l}\text { Tractor/ } \\
\text { Trailers }\end{array}$ & $\begin{array}{l}\text { Auto- } \\
\text { Rickshaw }\end{array}$ \\
\hline $9.00-10: 00$ & 380 & 24 & 11 & 809 & 0 & 0 & 2 & 64 \\
\hline $10: 00-11: 00$ & 563 & 31 & 21 & 1037 & 0 & 0 & 2 & 101 \\
\hline $11: 00-12: 00$ & 553 & 30 & 28 & 791 & 0 & 0 & 2 & 148 \\
\hline $12: 00-13: 00$ & 524 & 33 & 20 & 668 & 8 & 3 & 0 & 159 \\
\hline $13: 00-14: 00$ & 657 & 38 & 24 & 628 & 12 & 5 & 4 & 154 \\
\hline $15: 00-16: 00$ & 478 & 28 & 20 & 409 & 11 & 3 & 4 & 128 \\
\hline $16: 00-17: 00$ & 579 & 33 & 15 & 430 & 14 & 1 & 2 & 113 \\
\hline $17: 00-18: 00$ & 509 & 31 & 14 & 428 & 3 & 0 & 0 & 125 \\
\hline
\end{tabular}

\section{Table 3}

Traffic Volume (veh/h) at Qutubminar Direction 1

\begin{tabular}{|l|l|l|l|l|l|l|l|l|}
\hline & Car/Jeep & Mini Bus & Bus & $\begin{array}{l}\text { Scooter/ } \\
\text { Motor Cycle }\end{array}$ & $\begin{array}{l}\text { Mini } \\
\text { Truck }\end{array}$ & Truck & $\begin{array}{l}\text { Tractor/ } \\
\text { Trailers }\end{array}$ & $\begin{array}{l}\text { Auto- } \\
\text { Rickshaw }\end{array}$ \\
\hline $9.00-10: 00$ & 1849 & 9 & 36 & 876 & 106 & 10 & 8 & 83 \\
\hline $10: 00-11: 00$ & 1658 & 10 & 31 & 854 & 55 & 6 & 4 & 83 \\
\hline $11: 00-12: 00$ & 1758 & 7 & 29 & 863 & 72 & 12 & 6 & 94 \\
\hline $12: 00-13: 00$ & 1693 & 18 & 24 & 856 & 74 & 5 & 9 & 78 \\
\hline $13: 00-14: 00$ & 1658 & 12 & 34 & 884 & 77 & 6 & 3 & 94 \\
\hline $15: 00-16: 00$ & 1506 & 14 & 28 & 536 & 43 & 3 & 3 & 72 \\
\hline $16: 00-17: 00$ & 1831 & 9 & 30 & 788 & 17 & 4 & 4 & 63 \\
\hline $17: 00-18: 00$ & 1828 & 8 & 32 & 845 & 15 & 4 & 1 & 88 \\
\hline
\end{tabular}


Table 4

Traffic Volume (veh/h) at Qutubminar Direction 2

\begin{tabular}{|l|l|l|l|l|l|l|l|l|}
\hline Time & Car/Jeep & Mini Bus & Bus & $\begin{array}{l}\text { Scooter/ } \\
\text { Motor Cycle }\end{array}$ & $\begin{array}{l}\text { Mini } \\
\text { Truck }\end{array}$ & Truck & $\begin{array}{l}\text { Tractor/ } \\
\text { Trailers }\end{array}$ & $\begin{array}{l}\text { Auto- } \\
\text { Rickshaw }\end{array}$ \\
\hline $9.00-10: 00$ & 1804 & 3 & 26 & 1358 & 52 & 15 & 3 & 64 \\
\hline $10: 00-11: 00$ & 1808 & 7 & 25 & 944 & 80 & 8 & 9 & 68 \\
\hline $11: 00-12: 00$ & 1737 & 8 & 22 & 689 & 57 & 13 & 7 & 46 \\
\hline $12: 00-13: 00$ & 1299 & 29 & 40 & 654 & 66 & 9 & 4 & 63 \\
\hline $13: 00-14: 00$ & 1335 & 7 & 19 & 635 & 49 & 11 & 11 & 57 \\
\hline $15: 00-16: 00$ & 1204 & 20 & 17 & 508 & 39 & 9 & 8 & 37 \\
\hline $16: 00-17: 00$ & 1820 & 9 & 19 & 1035 & 35 & 8 & 2 & 49 \\
\hline $17: 00-18: 00$ & 1809 & 11 & 17 & 1140 & 30 & 7 & 7 & 61 \\
\hline
\end{tabular}

\section{Table 5}

Monitored Noise Level at Rithala

\begin{tabular}{|l|l|l|l|l|l|l|l|l|}
\hline Time & \multicolumn{2}{l}{ Rithala (Operational Corridor) } \\
\hline & \multicolumn{3}{l}{ Direction 1 } \\
& L10 & L50 & L90 & Leq & L10 & L50 & L90 & Leq \\
\hline & 76.6 & 72.2 & 67.6 & 73.7 & 81.5 & 74.0 & 69.5 & 76.6 \\
\hline $9.00-10: 00$ & 78.1 & 73.0 & 69 & 74.5 & 78.5 & 73.5 & 69.5 & 75.0 \\
\hline $10: 00-11: 00$ & 78.1 & 74.5 & 68.7 & 76.1 & 80.5 & 75.0 & 70.5 & 76.8 \\
\hline $11: 00-12: 00$ & 80.8 & 75.5 & 69.5 & 77.8 & 77.0 & 72.5 & 69.0 & 73.6 \\
\hline $12: 00-13: 00$ & 69.1 & 73.8 & 69.5 & 75.4 & 80.5 & 74.0 & 68.5 & 76.6 \\
\hline $13: 00-14: 00$ & 79.5 & 75.2 & 71.0 & 76.5 & 77.5 & 72.0 & 69.0 & 73.3 \\
\hline $15: 00-16: 00$ & 78.8 & 74.5 & 67.8 & 76.7 & 79.0 & 72.0 & 68.0 & 74.2 \\
\hline $16: 00-17: 00$ & 79.5 & 74.5 & 69.0 & 76.5 & 80.0 & 76.0 & 72.0 & 77.1 \\
\hline $17: 00-18: 00$ & & & & & & & & \\
\hline
\end{tabular}

\section{Table 6}

Monitored Noise Level at Qutubminar

\begin{tabular}{|l|l|l|l|l|l|l|l|l|}
\hline Time & \multicolumn{2}{l}{ Qutubminar (During Construction Phase) } \\
\hline & \multicolumn{3}{l}{ Direction 1 } & \multicolumn{3}{l}{ Direction 2 } \\
\hline & L10 & L50 & L90 & Leq & L10 & L50 & L90 & Leq \\
\hline & 84.5 & 78.8 & 75.1 & 80.4 & 83.0 & 78.3 & 75 & 79.4 \\
\hline $9.00-10: 00$ & 83.9 & 79.5 & 76.4 & 80.5 & 80.5 & 77.0 & 73.5 & 77.9 \\
\hline $10: 00-11: 00$ & 78.5 & 72.7 & 68.0 & 74.7 & 78.5 & 73.5 & 69.5 & 74.6 \\
\hline $11: 00-12: 00$ & 80.4 & 76.6 & 70.5 & 78.4 & 79.5 & 72.5 & 67.5 & 75.1 \\
\hline $12: 00-13: 00$ & 78.0 & 74.0 & 69.0 & 75.5 & 83.0 & 77.0 & 72.5 & 79.0 \\
\hline $13: 00-14: 00$ & 83.5 & 76.0 & 71.5 & 79.0 & 83.5 & 78.3 & 71.0 & 81.0 \\
\hline $15: 00-16: 00$ & 81.0 & 77.5 & 71.5 & 79.1 & 80.0 & 77.0 & 75.0 & 77.5 \\
\hline $16: 00-17: 00$ & 83.0 & 76.0 & 72.3 & 77.7 & 78.5 & 72.5 & 68.0 & 74.5 \\
\hline $17: 00-18: 00$ & & & & & & & & \\
\hline
\end{tabular}




\section{Table 7}

Spot Speed Study at Selected Locations

\begin{tabular}{|c|c|c|c|c|}
\hline \multirow{3}{*}{ Vehicle Type } & \multicolumn{4}{|c|}{ Average Spot speed $(\mathrm{km} / \mathrm{h})$} \\
\hline & \multicolumn{2}{|l|}{ Rithala } & \multicolumn{2}{|l|}{ Qutubminar } \\
\hline & Direction 1 & Direction 2 & Direction 1 & Direction 2 \\
\hline Car/Jeep & 52.20 & 53.32 & 33.31 & 35.12 \\
\hline Mini Bus & 35.29 & 34.73 & 34.66 & 34.78 \\
\hline Bus & 37.38 & 37.15 & 38.19 & 36.98 \\
\hline Motorcycle & 51.46 & 52.71 & 39.81 & 40.45 \\
\hline Mini truck & 39.34 & 40.82 & 25.08 & 25.26 \\
\hline Truck & 39.22 & 38.33 & 32.63 & 31.12 \\
\hline Tractor/Trailer & 25.85 & 25.83 & 26.81 & 26.77 \\
\hline Auto-Rickshaw & 27.87 & 28.89 & 29.51 & 28.93 \\
\hline
\end{tabular}

\section{Table 8}

Ambient Noise Standards in India

\begin{tabular}{|l|l|l|}
\hline \multirow{2}{*}{ Area } & Leq $(\mathbf{d B A})$ & Night Time** \\
\cline { 2 - 3 } & Day Time* & 70 \\
\hline Industrial & 75 & 55 \\
\hline Commercial & 65 & 45 \\
\hline Residential & 55 & 40 \\
\hline Silence Zone & 50 & \\
\hline
\end{tabular}

${ }^{*}$ Daytime 6 A.M. to 9 P.M. i.e. 15 hours

${ }^{* *}$ Night time 9 P.M. to 6 A.M. i.e. 9 hours

***Areas up to 100 meter around certain premises like hospital, educational institute and courts

Source: The Noise Pollution (Regulation and Control) Rules, $C P C B$

\section{Methodology of Analysis}

Traffic noise calculation is an important component while designing noise barriers. Prediction of noise basically involves consideration of the nature of source and receiver, propagation along the paths of source and receiver and location of receiver. Many noise prediction methodologies are being used world wide for calculating noise impact from road sources and most of them are empirical. This study analysis is based on the application of US's Federal Highway
Administration Model (FHWA, 2000). Mishra et al. (2010) studied the traffic noise characteristics of bus rapid transit system (BRTS) corridor in Delhi and suggested design of noise barrier along the corridor to curb the noise pollution through the appliance of developed modified FHWA model in Microsoft Excel Sheet. Shukla et al. (2009) and Shukla (2011) also applied FHWA model to predict the traffic noise level as well as to design noise barriers at different locations in Lucknow city and compared these values with observed noise 
level data and found the best suitability of this model in this particular city. Gupta (1979) built up a relationship between the vehicular noise and stream flow parameters (Shukla et al., 2009).

$L_{10}=18.092433+19.90357 \times \log _{10}(\mathrm{Q} w) \mathrm{dB}(\mathrm{A})$

Where,

$Q w=$ traffic volume in EPCU (Equivalent Passenger Car Unit) / hr.

Jain and Parida (2004) conducted their study at various locations of Delhi, Jaipur, Chandigarh, Allahabad and Lucknow city of India and designed noise barrier at sensitive zones. Traffic noise levels in the vicinity of roadway can be predicted on the basis of individual vehicle noise levels, vehicle volume, speed, observer distance and other correlations. The value of $L e q$ is determined from the following equation (Eq. (2)):

$L e q=L_{0}+\Sigma L_{i}$

Where, $L_{0}=$ basic noise level for a stream of vehicles in $\mathrm{dBA}$, and

$L_{i}=$ adjustment applied in dBA.

Basic noise level is the noise emitted by a particular class of vehicle at a distance of $15 \mathrm{~m}$ from the center of the inner lane at a given speed and road surface. In this model vehicles are divided into seven different categories as given in Table 9.

\section{Table 9}

Basic Noise Level $\left(L_{0}\right)$ for Identified Vehicle Categories

\begin{tabular}{|l|l|l|}
\hline Category & Reference Mean Emission & Height of Source $(\mathbf{m})$ \\
\hline Car/Jeep/Van & L0 $=32.372 \log 10(\mathrm{~S})+15.891$ & 0.00 \\
\hline Scooter/Motorcycle & $\mathrm{L} 0=35.871 \log 10(\mathrm{~S})+8.979$ & 0.00 \\
\hline LCV/Mini Bus & $\mathrm{L} 0=31.212 \log 10(\mathrm{~S})+23.26$ & 0.70 \\
\hline Buses & $\mathrm{L} 0=41.378 \log 10(\mathrm{~S})+8.873$ & 1.50 \\
\hline Trucks & $\mathrm{L} 0=43.248 \log 10(\mathrm{~S})+6.597$ & 1.50 \\
\hline Three-Wheeler & $\mathrm{L} 0=0.2202 \log 10(\mathrm{~S})+61.51$ & 0.00 \\
\hline Tractor Trailor & $\mathrm{L} 0=6.411 \log 10(\mathrm{~S})+73.065$ & 1.50 \\
\hline
\end{tabular}

Source: Jain and Parida (2004); Shukla (2011)

Combined noise level for each class of vehicle

(i) and each roadway ( $j$ ) is (Eq. (3)):

$L_{e q i j}=L_{0}+A_{v i j}+A_{D i}+A g+A_{B}+A_{F}+A_{S}$

Equivalent noise level due to traffic at the receiver (Eq. (4)):

$L_{e q}=10 \log \left(\sum \sum 10^{L e q i j / 10}\right)$

\section{Analysis and Results}

\subsection{Comparative Analysis between Predicted and Observed Noise Level}

On the basis of various data analysis, Fig. 2 shows the comparative figure of the predicted and observed noise levels along operational corridor in both directions 
of Rithala. It is depicted from the above figure that the value of observed noise level is higher than the predicted value at both direction of the Rithala location. Fig. 3 states the comparative study of predicted and observed noise level assessment at MRTS under construction at both sides of Qutub location. Due to construction, the predicted and observed values are very higher than the standard values.
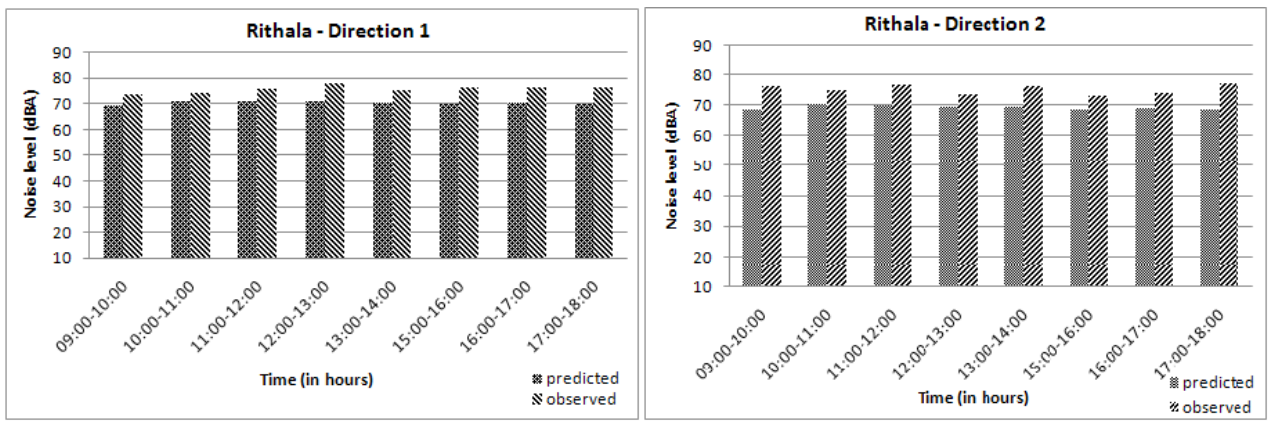

Fig. 2.

Predicted and Observed Noise Levels in both Direction of Rithala Metro Corridor
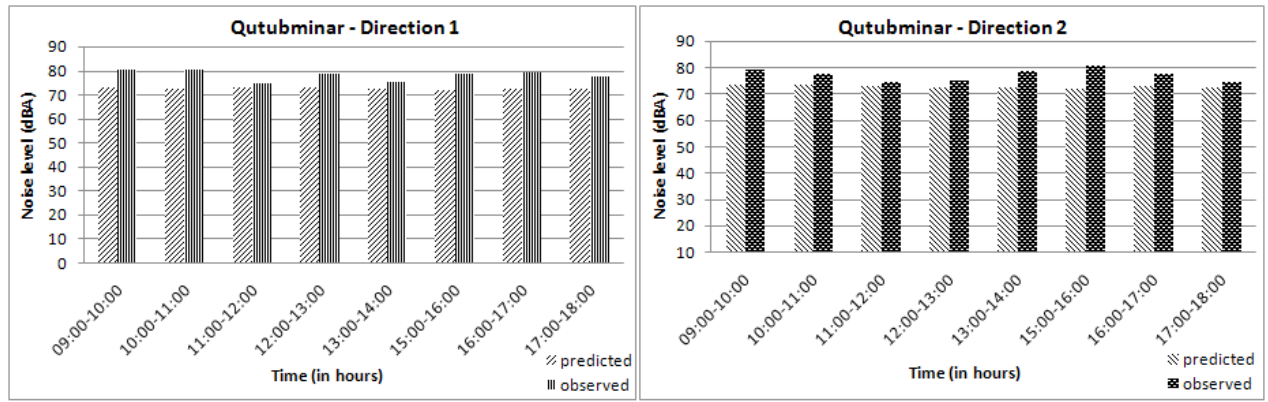

Fig. 3.

Predicted and Observed Noise Levels in both Direction of Qutubminar Metro Corridor

\subsection{Perception Based Analysis of Operational MRTS Corridor}

Along with modelling part, the questionnaire based survey was also carried out among the residents living in the vicinity of operational corridor. The basic aim behind this survey was to take the opinion of the commuters regarding the changes observed after the implementation of the new public transport mode i.e. MRTS. To estimate the percentage level regarding various issues to environment, a number of questions have been framed and asked to commuters to know their opinion. Table 10 shows the questionnaire based responses of various respondents. 


\section{Table 10}

Questionnaire Responses

\begin{tabular}{|c|c|c|c|c|}
\hline \multirow{2}{*}{ S. No. } & \multirow{2}{*}{ Questions } & \multicolumn{2}{|c|}{ Response (\%) } & \\
\hline & & Yes & No & \\
\hline 1. & Initial Noise problem in surrounding & 72 & 28 & \\
\hline 2. & Any particular noise problem annoys & 76 & 24 & \\
\hline 3. & Reduction in travel time due to Metro & 92 & 8 & \\
\hline 4. & Parking problem due to MRTS & 28 & 72 & \\
\hline 5. & Role of MRTS in local expansion & 70 & 30 & \\
\hline 6. & Effect of dust particle on health during MRTS construction & 85 & 15 & \\
\hline \multirow[t]{2}{*}{7.} & Loss of Flora during construction & 35 & 65 & \\
\hline & & Enhanced & Depreciated & No difference \\
\hline 8. & Security due to Metro & 80 & 16 & 4 \\
\hline 9. & Improvement in comfort level & 96 & 4 & - \\
\hline 10. & Noise Pollution after Metro operation & 42 & 36 & 24 \\
\hline 11. & Traffic congestion after introducing MRTS & 34 & 57 & 9 \\
\hline
\end{tabular}

From the perception based analysis, the major outcomes which are found that most of the people are satisfied in terms of reduction in travel time, congestion, pollution after the introduction of mass rapid transit system. On the other hand, the residents are also found in favour of security enhancement and comfort level improvement due to metro operation. Although a lot of flora destruction occurred during the construction phase.

\subsection{Height of Noise Barrier}

Scholes and Sargent (1971) suggested design rules for estimating the effect of long noise barriers on the propagation of motorway noise peaks in terms of $L_{10}$. Nelson and Godfrey (1974) studied the road traffic noise in rural environment. During their study they measured the traffic noise alongside 26 miles of the A66 within the Lake District National Park and in the towns of Keswick and Coker mouth and they built a $50 \mathrm{~dB}(\mathrm{~A}) L_{10}$ contour for road traffic noise. Rithla location has two types of land use, one side commercial area (Direction 1) and other side residential area (Direction 2). Data analysis of commercial area presents the prerequisite 2.2 meter height of barrier just near the road edge. Whereas residential area of Rithala location shows that there is a requirement of 2.9 meter height of the barrier. Since two meter height of brick wall as a barrier already exists near to residential area along the road in Direction 2 of Rithala location. Therefore, to achieve the desired noise level (45 dBA); the existing barrier height should be increased by 0.9 meter. Due to higher level of noise level at this residential location, only simple barrier (brick wall) is not sufficient to minimize the noise level up to desired level i.e. $45 \mathrm{dBA}$, but also further reduction can be achieved through the application different kind of material on the basis of their absorption coefficient which can be used as a filler during barrier installation. Along with the designing of noise barrier in order to reduce more noise levels at higher floor of the buildings, acoustic treatment of building façade, like applying sound absorbing materials on the external walls etc. is suggested. Fig. 4 illustrates the existing noise level and the noise level after the installation of noise barrier along both the commercial and residential sides of Rithala location. 

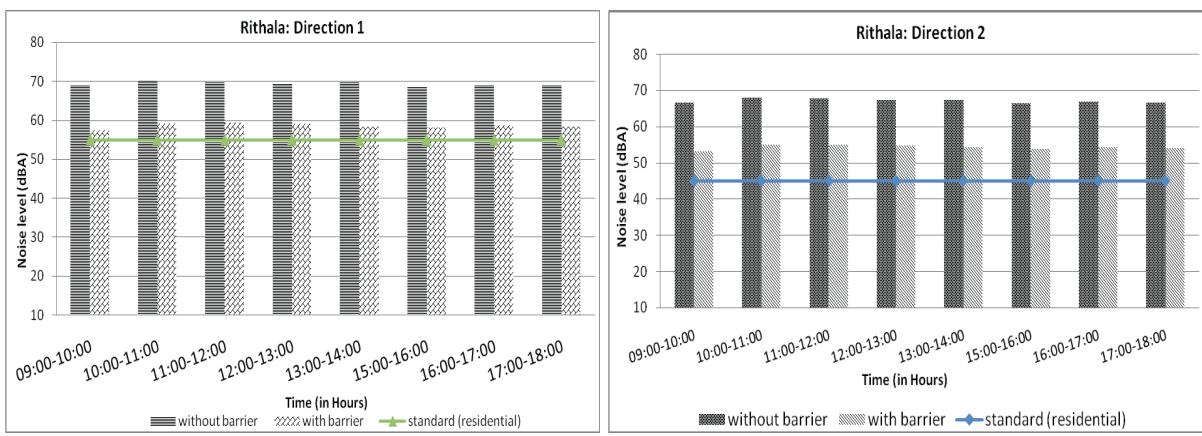

Fig. 4.

Noise Level Reductions after the Installation of Noise Barrier

\section{Conclusion}

Based on the study it is concluded that the noise pollution levels that were observed and predicted through the models have exceeded the CPCB standards. This is alarming and considering the fact that the traffic volume is going to increase in coming years. The share of public transport in total noise pollution is smaller than private but still exceeds the standards. In response to this, certain measure has been suggested to curb the noise pollution in the vicinity of the concerned transport corridors. These mainly include construction of noise barriers along the road. Another effort on our part has been to present the social impact of these transportation systems on the lives of the residents and road users. In this regard, road side surveys revealed many aspects which should be looked into. Indirect mitigatory measure like encourage the people towards the use of public transport can also be an important step towards the reduction of environmental pollution.

\section{Acknowledgements}

The authors are thankful for the assistance of Centre for Transportation Systems (CTRANS) and Department of Management Studies (DOMS), IIT Roorkee.

\section{References}

Economic Survey of Delhi. 2012-2013. Available from Internet: <http://delhi.gov.in/wps/wcm/connect/ DoIT_Planning/planning/misc./economic + survey+ of+delhi+2012-13>.

Federal Highway Administration (FHWA), US. 2000. FHWA Highway Noise Barrier Design Handbook.

Galilea, P.; Ortúzar, J.de D. 2005. Valuing noise level reductions in a residentiallocation context, Transportation Research Part D: Transport and Environment. DOI: http:// dx.doi.org/10.1016/j.trd.2005.04.004, 10(4): 305-322.

Gupta, A. 1979. Relationship between vehicles noise and stream flow parameters, M.E. dissertation, Civil Engineering Deptt. University of Roorkee, Roorkee, India. 
Jain, S.S.; Parida, M. 2004. Urban Transport Environment Interaction. AICTE Nationally Co-ordinate Project Final Report submitted to AICTE, New Delhi, India.

Jose, A.; Pacheco, M.A.O.; Santiago, J.A.; Eduardo, B. 2012. Vehicle Noise Emission Levels in Bogota City. In Proceedings of the Inter Noise 2012, New York, USA.

Kumar, K.; Jain, V.K.; Rao, D.N. 1998. A predictive model of noise for Delhi, The Journal of the Acoustical Society in America. DOI: http://dx.doi.org/10.1121/1.421260, 103(3): 1677-1679.

Mishra, R.K.; Parida, M.; Rangnekar, S. 2010. Evaluation and analysis of traffic noise along bus rapid transit system corridor in Delhi, International Journal of Environmental Science and Technology (IJEST). DOI: http://dx.doi. org/10.1007/BF03326183, 7(4): 737-750.

Mohammadi, Gh. 2009. An Investigation of Community Response to Urban Traffic Noise, Iranian Journal of Environmental Health Science \& Engineering, 6(2): 137-142.

Nelson, P.M.; Godfrey, N. 1974. Predicting road traffic noise in the rural environment. TRRL Laboratory Report 642 , Berkshire.

Novačko, L.; Petrović, M.; Barić, D. 2014. Application of macroscopic modelling in assessing noise level in urban areas, International Journal for Traffic and Transport Engineering. DOI: http://dx.doi.org/10.7708/ ijtte.2014.4(1).09, 4(1): 117-127.
Scholes, W.E.; Sargent, J.W. 1971. Desigining against noise from road traffic, Applied Acoustics. DOI: http:// dx.doi.org/10.1016/0003-682X(71)90017-X, 4(3): 203-234.

Shukla, A.K. 2011. An approach for design of noise barriers on flyovers in urban areas in India, International Journal for Traffic and Transport Engineering, 1(3): 158-167.

Shukla, A.K.; Jain, S.S.; Parida, M.; Srivastava, J.B. 2009. Performance of FHWA model for predicting traffic noise: A case study of metropolitan city, Lucknow (India), Transport. DOI: http://dx.doi.org/10.3846/16484142.2009.24.234-240, 24(3): 234-240.

The Noise Pollution (Regulation and Control) Rules. Central Pollution Control Board (CPCB), New Delhi, India. Available from Internet: <http://www.cpcb.nic. in/divisionsofheadoffice/pci2/noise_rules_2000.pdf $>$.

United States Environmental Protection Agency. 2001. Our Built and Natural Environments: A Technical Review of the Interactions Between Land Use. Transportation and Environmental Quality (EPA 231-R1e002). US EPA, Washington D.C., US.

Zannin, P.H.T. 2008. Occupational noise in urban buses, International Journal of Industrial Ergonomics. DOI: http:// dx.doi.org/10.1016/j.ergon.2006.06.014, 38(2): 232-237.

Zekry, F.G. 2009. Assessment and Analysis of Traffic Noise Pollution in Alexandria City, Egypt, World Applied Sciences Journal, 6(3): 433-441. 